\title{
Mechanical Behaviour of PLA and PHBV Based Lignocellulosic Composite Plates
}

\author{
M. Selwin, N. Rajini
}

\begin{abstract}
The knowledge of $3 D$ printing material used in $3 D$ printing technique is so abundant. Even though there are many critical issues in practical applications. This paper reports the comparison study of the Tensile, Flexural and Impact properties of Environmental friendly composites. This composite material is intended to be used as a replacement for the current $3 D$ printing material. The composite was prepared in compression molding/Injection molding technique under $150 \mathrm{~kg} / \mathrm{cm} 2$ pressure. This work consists of three specimens. One specimen is Poly Hydroxy Butyrate co Valerate (PHBV) and Sansevieria Roxburghiana. Second specimen is Poly Lactic Acid (PLA) and Sansevieria Roxburghiana and the last specimen is Pure PLA plate. The tensile, impact, flexural strength of pure PLA is comparatively better than the other two composite mixture plates. When comparing the fiber mixture of PLA and PHBV plates the PLA mixture possess greater mechanical properties. The research is further extended by changing the proportion of fiber and also improving the fiber lengths.
\end{abstract}

Keywords : Bio composites, Poly Hydroxy Butyrate co Valerate (PHBV), Sansevieria Roxburghiana, Polylactic Acid (PLA).

\section{INTRODUCTION}

[1] $S_{\text {ansevieria Trifasciata fiber which has a great impact }}$ in textile industries is a lignocellulosic fiber. Water retting is one of the notable technique that is used for the extraction of Sansevieria Trifasciata from its leaves. By improvising the various techniques the various geometrical and mechanical behavior have been measured in the lab. [2] This article surveys the procedure of provocative response that will be normal after implantation of PLA, and it features explicit cases in which the incendiary response can result in wellbeing concerns. The creators likewise survey chosen cases from various therapeutic fields to show conceivable clinical symptoms coming about because of its utilization. [3] PLA is delivered on huge scale and utilized for different applications, for example bundling for prescription, horticulture and material. Sadly, the weakness of PLA is significant disadvantage to limit its applications. So as to conquer these impediments, improvement the durability of PLA by copolymerization, plasticization, mixing or by the generation of filled

Revised Manuscript Received on December 29, 2019.

M. Selwin*, Department of Mechanical Engineering, KARE, Krishnankoil, India. Email: selwin123@gmail.com

N. Rajini, Department of Mechanical Engineering, KARE, Krishnankoil, India.Email: rajiniklu@gmail.com composites has been of intrigue. [4] The inexhaustible aliphatic polyesters of poly (hydroxyacid)-type homo polymers and copolymers comprising of poly lactic corrosive (PLA) PLA has pulled specifically consideration as a ultimate alternate for conventional plastics. [5] When comparing to other printing techniques such as Screen printing and inkjet technology 3D printing possess a remarkable impacts on engineering texture and material functionalization. The main objectives is to customize the usage of water, various bio components and to avoid various losses to improve the natural impacting and profit. [6] This work suggests the various parameters of Sansevieria natural fiber as fortification in the readiness of incompletely bio friendly green composites. The impact of fiber content on mechanical behavior of composite was investigated and found that rigidity and effect quality at greatest fiber content were 2.55 and 4.2 occasions to that of unadulterated tar, individually. [7] As per the formulated re-testing talked in this work, when suitable trial outputs can't be created, the weakness evaluation can be performed by utilizing a reference weariness bend with negative backwards incline equivalent to 5.5 and continuance limit. AM PLA is portrayed by a weakness act like the one of PLA produced utilizing customary and entrenched advancements. [8] The diffusive turning of PHBV filaments which were spun from arrangement utilizing a scope of polymer fixations, turn speed and spinneret to gatherer separates. [9] The effect of using a combination of substrates on the synthesis of PHBV which indicates that PHBV was synthesized only when fructose was used as the sole carbon source. [10] The study found that the relative porosity is managed to 80 percentage with maximum surface area while developing a PHBV specimen using SLS. [11] By comparing the compatibility with PHBV-g-MA this work suggests the techniques for fabricating PHBV/PBS blends. It incorporate the methods to manage the structural and heat conducting properties. [12] Biodegradable curcumin-stacked electro spun PHBV nanofibers were acquired with imperfection free morphology and their normal distances across extended from $207 \pm 56$ to $519 \pm 15 \mathrm{~nm}$. [13] PHBV films with dynamic fundamental oil mixes were exceptionally compelling against $\mathrm{L}$. innocua and E.coli in vitro tests, yet they were significantly less viable in the genuine substances tried, except for the impact against E. coli in cheddar tests covered with PHBV-EU or PHBV-CLO films. [14] The impacts of g-illumination on PHBV/PLA: $50 / 50 \mathrm{w} / \mathrm{w}$ mixes brought about solid adjustments in the substance structure, particularly after $100 \mathrm{~kg}$ of assimilated portion. [15] 
Responsive expulsion convention for blending PHBV-g-GMA with a high GMA joining rate and few side responses.

\section{Objectives of the work:}

To check the variation in tensile property of PHBV and PLA with Sansevieria Fiber.

To compare the flexural behavior of PLA and PHBV with Sansevieria Fiber.

To analyze the impact behavior of PHBV and PLA

With the above mentioned studies the work is further extended and tested for making this as a replacement for conventional 3D printing material.

\section{MATERIALS}

\section{A. Natural Fibers}

\section{Sansevieria Roxburghiana}

The warm conductivity of the fiber diminishes with the expansion of fiber content. The expansion of Sansevieria decreases the Heat Release Rate. At the point when consumed it discharges more carbon dioxide than pitch composite. The rigidity of Sansevieria fiber is 2.55 occasions more prominent than gum and the effect quality is 4.2 occasions more prominent than the pitch. Elasticity of composite is expanded by $18.16 \%, 36.49 \%, 102.97 \%$, and $155.24 \%$ over virgin polyester at $0.12,0.21,0.28$, 0.36 volume division of filaments individually [6].

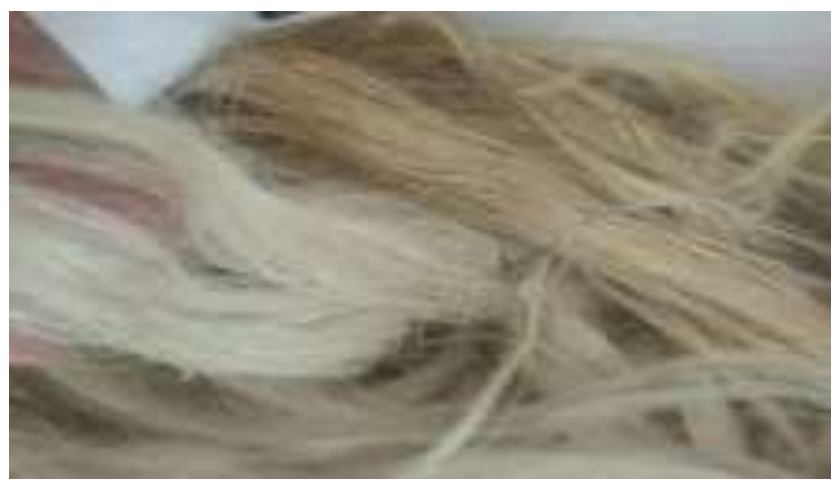

Fig.1. Extracted Sansevieria

\section{B. Polylactic corrosive}

Poly (lactic corrosive) or Polylactic corrosive or polylactide (PLA) is an environmental friendly biocompatible product prepared from corn starch, custard roots, chips or starch, or sugarcane. PLA had the second highest utilization volume of any natural plastic universally in 2010. [16]

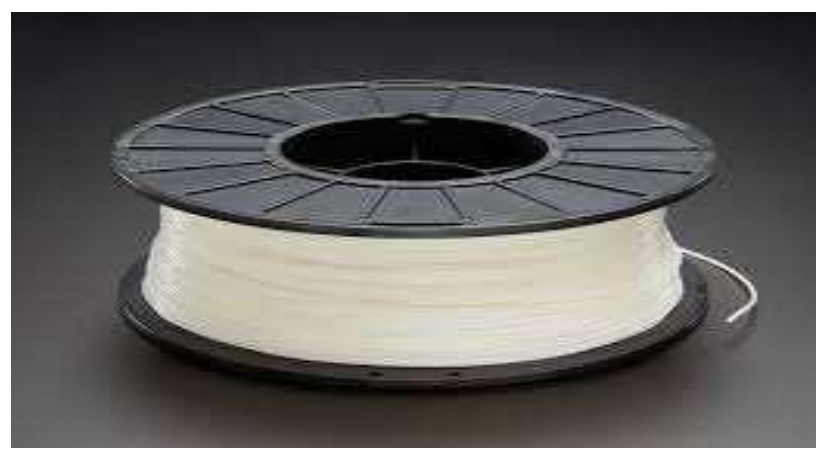

Fig.2. PLA winding

\section{Properties of Poly Hydroxy Butyrate Co Valerate}

PHBV is obtained from bacteria which is biodegradable, non- toxic and bio compatible. It is very brittle in nature. It possess low elongation. The impact resistance of PHBV is also very low. When disposed it degrades into carbon dioxide and water. PHBV just like fats to humans it is the energy source to micro-organism. Enzymes produced by them degrades it and are consumed. The thermal stability of PHBV is very low with primitive mechanical properties. It has very high processing difficulties. [17]

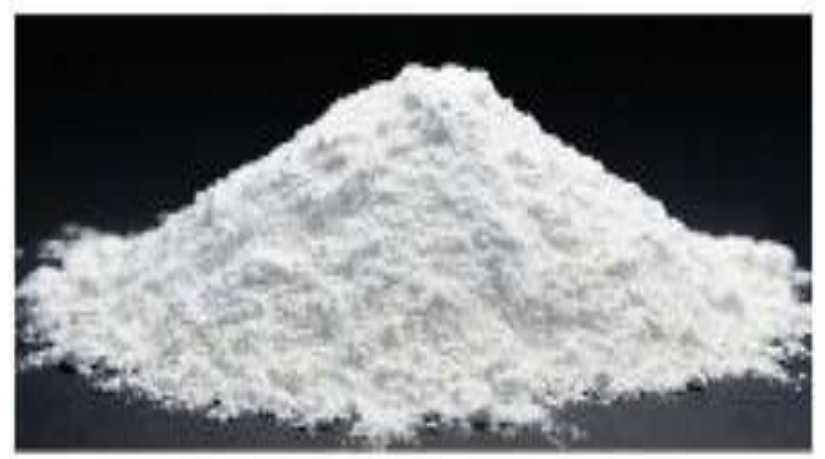

Fig.3. PHBV Powder

\section{PROBLEM DEFINITION}

The PLA material which is utilized in the $3 \mathrm{D}$ printing strategy is a standout amongst the most boundless biomass-based, biodegradable (compostable) and biocompatible polymers. It is water-insoluble, can be either straightforward or semi- straightforward relying upon polymer crystallinity, and optically dynamic. The primary downsides of the material are high fragility, moderate crystallization rate, and high penetrability to gases. The ways for beating these issues are to utilize plasticizers, copolymerization with different segments, making composites, and mixing with different polymers [18].

So in order to find out an alternative to the pre-existing 3D printing material, a new composite has to be prepared which overcome its defects. Therefore a composite consisting of both Sansevieria Roxburghiana and Poly Hydroxy Butyrate co Valerate (PHBV) is to be prepared as sample 1. The 2nd Sample is prepared from Sansevieria Roxburghiana and Polylactic Acid (PLA). PHBV also possess the properties of brittleness and low impact resistance and the tensile strength of composite increased with the change in the volume fraction of fibers. Apart from this, to decrease the utilization of cost of the printing material and also to reduce the toxicity in the pre-existing material, this composite of PLA, PHBV and Sansevieria Roxburghiana will be more needful. Thus a biodegradable replacement can be made thereby reducing all the environmental impacts that the previous materials has incurred. Thus it can be opted as a better replacement in order to eliminate all the health hazards.

\section{METHODOLOGY}

The fabrication and mechanical testing PLA and Sansevieria based composite

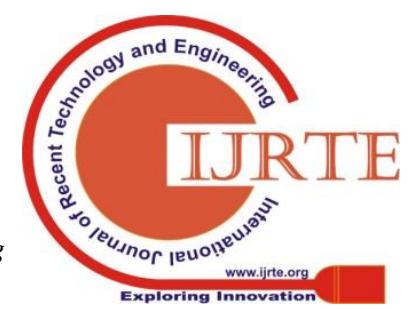


specimen is done by the methodology given below.

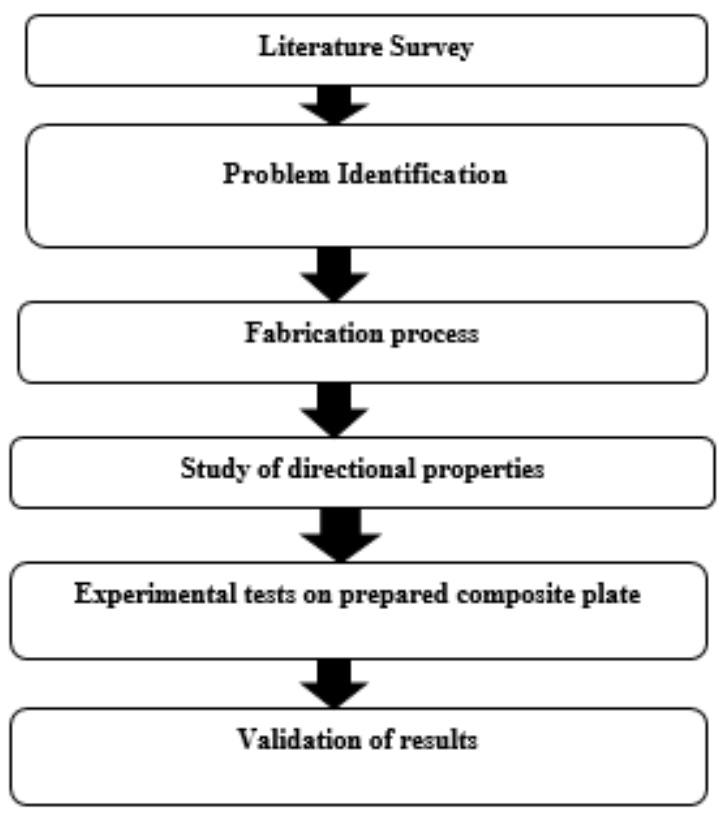

Fig.4. Methodology

\section{PROCESS OF FABRICATION}

\section{A. Injection Molding}

Infusion forming machine molds can be affixed in either an even or vertical position. Most of machines are evenly situated, yet vertical machines are utilized in some specialty applications, for example, embed forming, enabling the machine to exploit gravity. Some vertical machines likewise don't require the shape to be affixed. There are numerous approaches to attach the instruments to the platens, the most widely recognized being manual cinches (the two parts are dashed to the platens); be that as it may, water driven braces (chocks are utilized to hold the apparatus set up) and attractive clasps are additionally utilized. The attractive and water driven cinches are utilized where quick apparatus changes are required.

\section{B. Specimen Preparation}

Initially Sansevieria Roxburghiana fiber is prepared to be cut on different lengths such as $20 \mathrm{~mm}$. Pure fiber is separated which does not contain any green shades left over. Moreover, fine hair like structured fibers are separated in order to ensure that there are no thick pieces of fiber. This is done because such fibers can leads to improper plate preparation. The separated hair like fine fibers are eventually cut into different lengths. By injection molding the specimen is prepared for the following combinations.

The test results are plotted on graph having $\mathrm{X}$-axis as sample number and the $\mathrm{Y}$-axis parameter is taken as strength obtained in each test results in $\mathrm{N} / \mathrm{mm} 2$. Three specimen for each testing gives twelve results in total. The average of the results is calculated and it is considered for the final conclusion. Thus the results are obtained and are plotted in the form of a graph which helps in providing a

\section{TESTING OF COMPOSITES}

clear knowledge on the outcome of the results. The following table consists of the list of results obtained from the appropriate test samples with pure PLA, PLA with fiber and PHBV with fiber

Table.1. Test Results

\begin{tabular}{|c|c|c|c|c|}
\hline S.No & Test Parameters & Pure PLA & $\begin{array}{c}\text { PLA with } \\
\text { Fiber }\end{array}$ & $\begin{array}{c}\text { PHBV } \\
\text { with Fiber }\end{array}$ \\
\hline 1 & $\begin{array}{c}\text { Tensile Strength } \\
\left(\mathrm{N} / \mathrm{mm}^{2}\right)\end{array}$ & 41.56 & 19.38 & 18.65 \\
\hline 2 & $\begin{array}{c}\text { Flexural Strength } \\
\left(\mathrm{N} / \mathrm{mm}^{2}\right)\end{array}$ & 118.24 & 89.38 & 33.42 \\
\hline 3 & Impact (Joules) & 5.2 & 4.9 & 3.4 \\
\hline
\end{tabular}

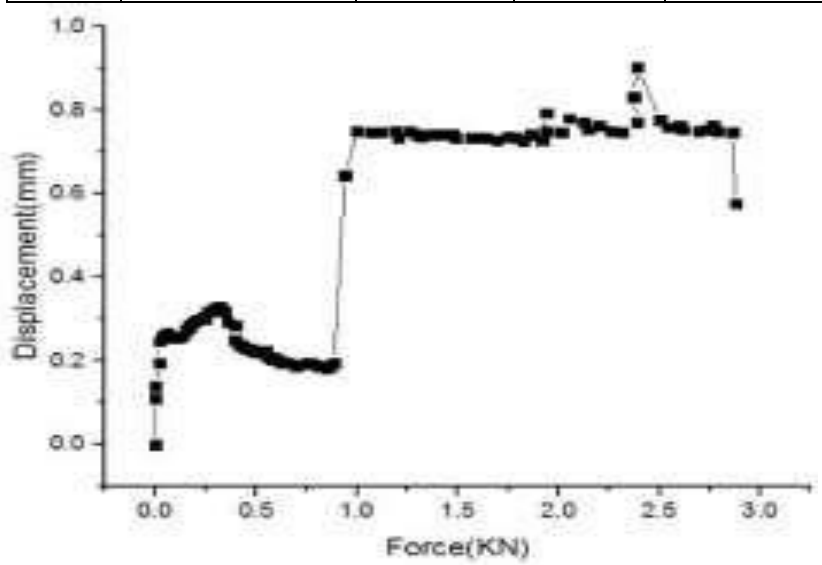

Fig.5. Load vs Displacement for PHBV and Fiber

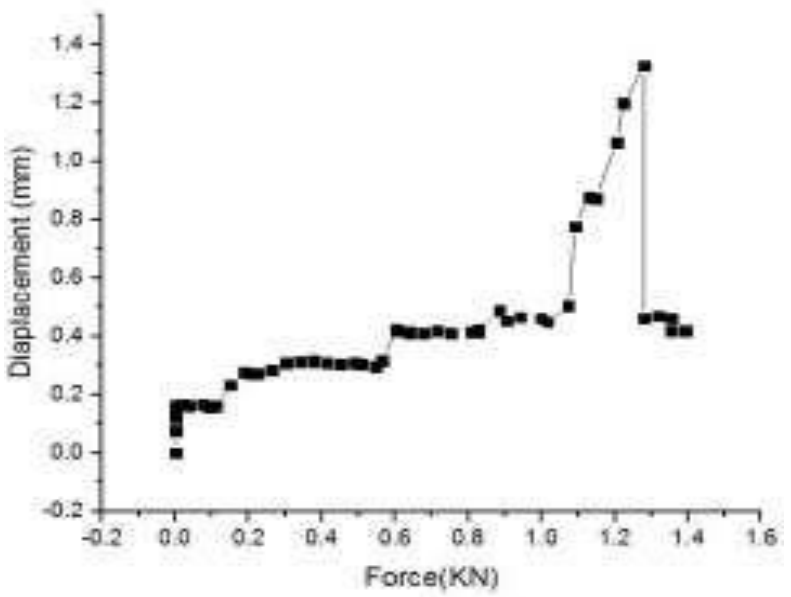

Fig.6. Load vs Displacement for PHBV and Fiber

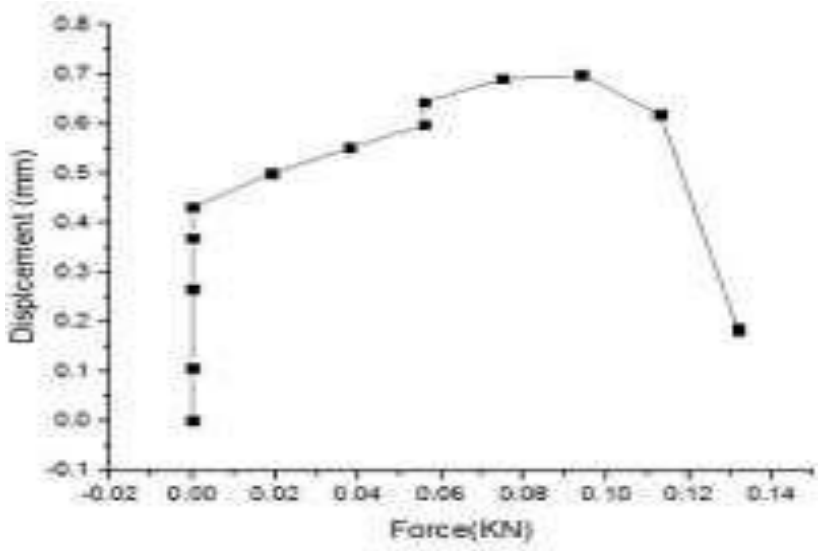

Fig.7. Load vs Displacement for PLA and Fiber 


\section{Mechanical behaviour of PLA and PHBV based lignocellulosic composite plates}

\section{CONCLUSION}

This study focuses on utilizing Sansevieria Roxburghiana fiber with PLA and PHBV powder as reinforcement towards producing bio degradable composites, thus bringing economic values to the Sansevieria Roxburghiana fiber. The Specimen of PLA, PLA fiber mixture and PHBV fiber mixture is fabricated and the results shows that the sample with pure PLA $20 \mathrm{~mm}$ fiber has the highest tensile strength when compared to PLA with fiber samples. Similarly, pure PLA contain high flexural strength and eventually PLA with fiber sample contain high impact strength. When comparing with the PHBV fiber mixture the PLA fiber mixture have higher Tensile, Flexural and Impact properties

\section{REFERENCE}

1. Kant, R., \& Alagh, P. "Extraction of Fiber from Sansevieria Trifasciata Plant and its Properties", International Journal of Science and Research (2013), ISSN: 2313-7064.

2. Yuval Ramot, Moran Haim-Zaida, Abraham Nyska, "Effect of peroxide on thermal and mechanical property of PLA in PLA method blend", Advanced drug delivery reviews (2016), vol. 107, pp. 153-162.

3. Moran Haim Zaida, Ramot, Y., Nyska, A., Markovitz, E., Dekel, A., Klaiman, G \& Maronpot, R. R. "Long-term local and systemic safety of poly (l-lactide-co-epsilon-caprolactone) after subcutaneous and intra-articular implantation in rats", Toxicologic pathology (2015), vol. 43(8), pp.1127-1140.

4. Mofokeng, J. P., \& Luyt, A. S, "Dynamic mechanical properties of PLA/PHBV, PLA/PCL, PHBV/PCL blends and their nanocomposites with TiO2 as nanofiller", Zx/Thermochimica acta (2015), vol. 613, pp. 41-53.

5. Sanatgar, R. H., Campagne, C., \& Nierstrasz, V, "Investigation of the adhesion properties of direct 3D printing of polymers and nanocomposites on textiles: Effect of FDM printing process parameters", Applied Surface Science (2017), vol.403, pp.551-563.

6. Ramanaiah, K., Prasad, A. R., \& Reddy, K. H. C, "Mechanical, thermophysical and fire properties of sansevieria fiber-reinforced polyester composites", Materials \& Design (2013), vol. 49, pp. 986991.

7. Ezeh, O. H., \& Susmel. L, "On the fatigue strength of 3D-printed polylactide (PLA)”, In Prcedia Structural Integrity (2018), vol. 9, pp.29-36.

8. Sarah J Upson, Tom O'Haire, Stephen J. Russell, "Centrifugally spun PHBV micro and nanofibres", Journal on Material Science and Engineering C (2017), vol. 76, pp.190-195.

9. Asieh Aramvash, Samira Hajizadeh-Turchi, Fatemeh Moazzenizavareh, "An Environmentally Friendly and Efficient Method for

10. Extraction of PHB Biopolymer with Non-Halogenated Solvents", Journal of Microbial Biotechnology (2015), Vol.25-11.

11. Sven H. Diermanna, Mingyuan Lua, Yitian Zhaoa, "Synthesis, microstructure, and mechanical behaviour of a unique porous PHBV scaffold manufactured using selective laser sintering", Journal of the Mechanical Behavior of Biomedical Materials (2018), vol.84, pp.151160.

12. Salima Kennouche, Nicolas Le Moigne, Mustapha Kaci, "Morphological characterization and thermal properties of compatibilized (PHBV)/ (PBS) /halloysite ternary nano composites", European Polymer Journal (2016), vol.75, pp.142-162.

13. Gozde Mutlu, Semih Calamak, Kezban Ulubayram, Eylem Guven, "Curcumin-loaded electrospun PHBV nanofibers as potential wounddressing material", Journal of Drug Delivery Science and Technology (2018), vol.43, pp.185-193

14. Raquel Requena, María Vargas, Amparo Chiralt, "Eugenol and carvacrol migration from PHBV films and antibacterial action in different food matrices", Journal of Food Chemistry (2019), vol.277, pp.38-45.

15. Idris Zembouai, Mustapha Kaci, Stephane Bruzaud, "Gamma irradiation effects on morphology and properties of PHBV/PLA blends in presence of compatibilizer and Cloisite 30B", Polymer Testing (2016), vol.49, pp.29-37

16. Ting Zheng, Zhan Zhang, Srishti Shukla, PHBV-graft-GMA via reactive extrusion and its use in PHBV/nanocellulose crystal composites, Carbohydrate Polymers (2019), vol. 205, pp.27-34.
17. Rafi Malik, Tarun Garg, Amit K. Goyal, and Goutam Rath, Polymeric nanofibers: targeted gastro-retentive drug delivery systems, Journal of drug Targetting, ISSN: 1061-186X (print), 1029-2330 (electronic).

18. Sunny Modi, Kurt Koelling, Yael Vodovotz, Assessing the mechanical, phase inversion, and rheological properties of poly-[(R)-3hydroxybutyrate-co-(R)-3- hydroxyvalerate] (PHBV) blended with poly-(L-lactic acid) (PLA), European Polymer Journal 2013, vol 49, pp.3681-3690.

19. Bin Li, Hongli Jiang, Lihua Guo, Hengchong Shi, Comparative Study on the Effect of Manchurian Ash and Larch Wood Flour on Mechanical Property, Morphology, and Rheology of HDPE/Wood Flour Composites, Journal of Applied Polymer Science (2008), vol. 107, pp. 2520-2530.

\section{AUTHORS PROFILE}

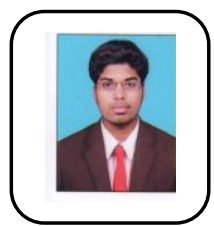

Mr. M. Selwin have completed his M.E in Manufacturing Engineering. His area of research is Natural Composites. He is currently working as an Assistant Professor in the Department of Mechanical Engineering in Kalasalingam Academy of Research and Education.

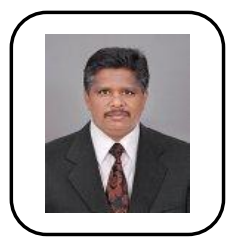

Dr. N. Rajini is a Professor in Kalasalingam Academy of Research and Education. His area of Research is Bio Composites. His Citation is 1320 , h index is 19 and i10 index is 32 . He is doing his project in Bio composites. He have several research collaborations with foreign countries. 